RAD Conference Proceedings, vol. 3, pp. 187-190, 2018

ISSN 2466-4626 (online) | DOI: 10.21175/RadProc.2018.40

www.rad-proceedings.org

\title{
UV INDEX FORECASTING IN THE VOJVODINA REGION
}

\author{
Zorica Podrascanin $^{1 *}$, Milica Atlagic ${ }^{1}$, Zoran Mijatovic ${ }^{1}$, Ana Firanj Sremac ${ }^{2}$ \\ ${ }^{1}$ University of Novi Sad, Department of Physics, Faculty of Sciences, Novi Sad, Serbia \\ ${ }^{2}$ University of Novi Sad, Faculty of Agriculture, Novi Sad, Serbia
}

\begin{abstract}
The UV index (UVI) values were calculated by an empirical model over Novi Sad (19.8 E, 45.3 N, $84 \mathrm{~m}$ ), Vojvodina region, Serbia, on clear sky days in all seasons. The ground-based ozone measurements for this location, the solar zenith angles and the distance from the Sun were used as input data for the model. At the same site, the UVI values were measured by a Yankee Environmental Systems (YES) UVB-1 pyranometer. The measured values were compared to the calculated values. This comparison was performed to improve this model for UVI forecast in the Vojvodina region. The differences between the modeled and measured data are small enough with root-mean-square differences of less than 0.8 in summer and 0.3 in winter, so we can conclude that this model could be used for UVI forecast for clear sky conditions in this region.
\end{abstract}

Key words: Empirical model, UV index, UV index forecast

\section{INTRODUCTION}

One of the major consequences of anthropogenic air pollution is the degradation of the stratospheric ozone layer, which increases the ultraviolet (UV) radiation that reaches the biosphere. UV radiation has a strong negative effect on live tissue. To track the effect of increased UV radiation and to use adequate protection measures, the value of UV radiation is needed. One way to gather information on the level of exposure is to determine the value of the UV index (UVI) $[1,4]$. The UVI is a measure of the biological effect of UV radiation and can be measured in real time, calculated or predicted.

The numerical models for UVI forecast are classified into three groups: 1) multiple-scattering spectral models, 2) fast spectral models, and 3) empirical models [2]. Multiple-scattering spectral models consider multiple scattering where multiple streams with different zenith angles are integrated to obtain irradiance. Fast spectral models include a wide range of models - from analytic functions all the way to models that are capable of handling multiple scattering with more than two streams. The empirical models present analytic functions that are generated directly from the measured UV index data using different types of parameterizations. The time that is required to calculate one UVI value is $10-100 \mathrm{~s}$ using multiplescattering spectral models, 0.1-10 $\mathrm{s}$ for fast spectral models and milliseconds for empirical models [2]. Huge differences in numerical times between models distinguish empirical models over other models in the particular areas for which the empirical model is suitable.

In this paper, the results from a previously developed empirical model [3] were compared to measurements from Novi Sad $\left(19.8^{\circ} \mathrm{E}, 45 \cdot 3^{\circ} \mathrm{N}, 84 \mathrm{~m}\right)$. The UVI was calculated for twenty clear sky days, five days for every season (every half hour) in order to compare this model with measured values. This comparison was performed to select the most suitable model for UVI forecast in the Vojvodina region.

\section{MATERIALS AND METHODS}

\subsection{Empirical model}

The empirical model from [3] is evaluated against the UVI measurements. The model estimates the UVI using the following expression:

$$
\frac{U V I}{U V A}=F \cdot X^{G}+\frac{H}{T C O}+J
$$

where $U V A$ is the empirically estimated UV index in the absence of ozone which depends on the solar zenith angle, the distance from the Sun to the Earth, the atmospheric extinction from molecular scattering and aerosols. UVA is calculated according to the observed Brewer spectrum multiplied by a weighting function, which is nonzero in the spectral region where ozone does not absorb significantly. Since we don't have Brewer measurements at our location we calculate the UVA following [3]. This mean that we assume the same atmospheric extinction and light scattering as it is in [3] and this parameter should be further analyzed and slightly modified to include the atmospheric extinction and light scattering specific for our locations. The coefficient values in Eq. 1 are: $F=2.0, G=1.62, H=$ 280.0, and $J=1.4$. The variable $X$ is the selected predictor given by

*zorica.podrascanin@df.uns.ac.rs 


$$
X=1000 \frac{\mu_{0}}{T C O}
$$

where $\mu_{o}$ is the cosine of the solar zenith angle, and TCO is the total column ozone. The formula (1) was developed for a wide range of ozone values and solar zenith angles and this is the main reason for using it in this paper.

\subsection{UVI and TCO measurements}

The UVI index has been measured in Novi Sad since 2003 using the Yankee Environmental Systems (YES) UVB-1 pyranometer. The measuring equipment is placed at the top of the building, to exclude the possibility of shadowing by surrounding objects at the campus of the University of Novi Sad. UVI measurements are collected every $30 \mathrm{~s}$, averaged over 10-minute time intervals and recorded in the database. From the observed time series (2006 - 2013), using random selection, we chose 20 clear sky days for UVI calculation and comparison. These days were separated seasonally (Table 1 ).

The satellite TCO data used in this paper are from the NASA site https://ozoneaq.gsfc.nasa.gov/tools/. The data were collected from two sensors OMPS (Ozone Mapping Profiler Suite) Nadir and OMI (Ozone Monitoring Instrument). In a situation in which the TCO values from both sensors exist, we used the average value. Unfortunately, data for the winter season are not complete; there are no data for 31.01.2012 or 07.02.2011 (Table 1). The TCO from the data of Global Forecast System (GFS, https://www.ncdc.noaa.gov/data-access/model-data/ model-datasets/global-forcast-system-gfs) will be used for everyday UVI forecast.

Table 1. Total ozone amount satellite measurements

\begin{tabular}{||c|c|c|c|c|c|c|c|c|c|c|c||}
\hline autumn & $\begin{array}{c}\text { OMPS } \\
\text { Nadir } \\
\text { Mappe } \\
r\end{array}$ & OMI & winter & $\begin{array}{c}\text { OMPS } \\
\text { Nadir } \\
\text { Mappe } \\
r\end{array}$ & OMI & spring & $\begin{array}{c}\text { OMPS } \\
\text { Nadir } \\
\text { Mappe } \\
r\end{array}$ & OMI & summer & $\begin{array}{c}\text { OMPS } \\
\text { Nadir } \\
\text { Mapper }\end{array}$ & $\begin{array}{l}\text { OMI } \\
15.10 .2007\end{array}$ \\
\hline 306 & 0 & $\begin{array}{c}29.01 .201 \\
0\end{array}$ & 0 & 360 & $\begin{array}{c}09.04 .200 \\
9\end{array}$ & 0 & 345 & 01.07 .2013 & 352 & 344 \\
\hline 16.10 .2007 & 0 & 281 & $\begin{array}{c}08.02 .2 \\
011\end{array}$ & 0 & 333 & 15.04 .2009 & 0 & 364 & 02.07 .2012 & 306 & 0 \\
\hline 17.10 .2007 & 0 & 282 & 10.02 .2011 & 0 & 323 & 26.04 .2011 & 0 & 340 & 03.07 .2012 & 313 & 0 \\
\hline 08.11 .2013 & 277 & 0 & - & - & - & 11.05 .2009 & 0 & 341 & 14.07 .2009 & 0 & 294 \\
\hline 19.11 .2009 & 277 & 0 & - & - & - & 19.05 .2009 & 0 & 315 & 21.07 .2009 & 0 & 309 \\
\hline
\end{tabular}

\section{RESULTS}

The UVI value was calculated every half hour on 18 clear sky days using TCO satellite measurements with the empirical model [3]. The obtained results were compared with those that were measured. The differences between the modeled and measured UVI values are evident in the correlation coefficient, which is lower during autumn and winter than that during summer and spring (Fig. 1).
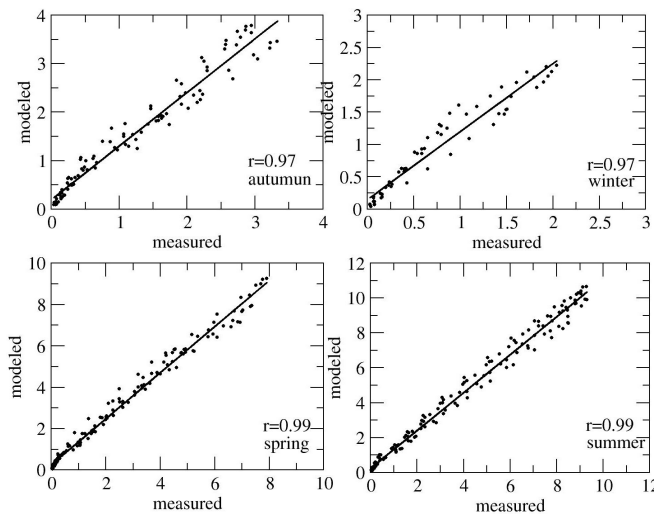

Figure 1. The correlation of UVI values calculated from measurements and the empirical model for the periods in Table 1.

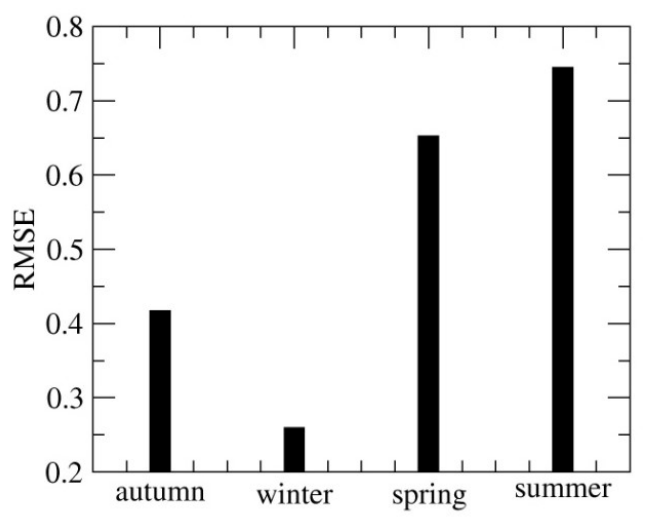

Figure 2. RMSE for UVI calculated by the empirical model

In Fig. 2, the RMSE is shown. The RMSE for UVI calculated by the empirical model has lower values in winter and autumn, and higher in spring and summer. Since the maximum values in spring and summer are in a range from $5-9$, and in winter and autumn $0.5^{-2}$, the differences in winter and autumn are higher than those in spring and summer according to maximum values. The model overestimated measured values with BIAS 0.3 in autumn and winter and 0.5 in spring and summer. The comparison of modeled and measured 
data shows satisfactory agreement. This conclusion supports the use of this empirical model for operational clear sky UVI forecasting at this location.

Since the terrain in the Vojvodina region is flat and fairy uniform, this model can be used for any location in this region. The ozone values in this small region rarely differ from place to place and the change in solar zenith angel, which is also small, will be the only reason for change in UVI values in different towns. Those facts enable as to start with the operational clear sky UVI forecast for this region. For selected towns the model is stared every day at the midnight and the UVI values is forecasted every hour for the next 24 hours. The clear sky UVI forecast is publicly available at the website of the Faculty of Sciences (PMF), University of Novi Sad (https://www.df.uns.ac.rs).

In Fig. 3 the view of the clear sky UVI forecast at the website was presented. The UVI forecast is graphically presented for each town separately. UVI values that may be harmful to humans have been noted by different colors. The very high and extreme risk of harm from unprotected sun exposure is noted by red and violet, respectively.

\section{UVI forecast at site \\ Prognoza UV indeksa za: accept}

Novi Sad $\quad$ potvrdite

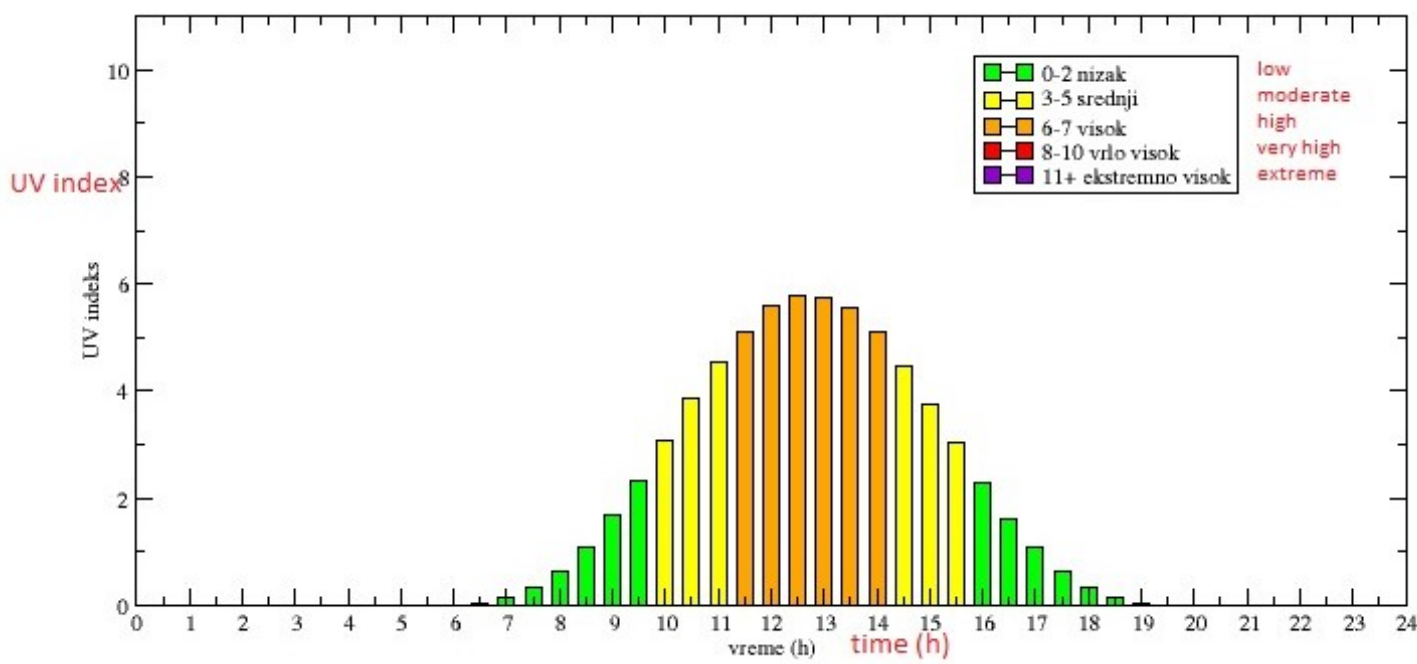

Figure 3. The example of webpage view of clear sky UV index forecast at https://www.df.uns.ac.rs/ for Novi Sad

\section{CONCLUSION}

This comparison between modeled and measured UVI values in Novi Sad was performed to assess the possibility of using the empirical model from [3] for clear sky UVI forecast in the Vojvodina region. The differences between the modeled and measured data are small enough (RMSE less than 0.8 in spring and summer, less than 0.5 in autumn and less than 0.3 in winter), so we can say that this model can be used for clear sky UVI forecasting. Due to the flat terrain in this region, this model could be used for clear sky UVI forecasting fort the entire region. The UVI forecasts have been done for selected towns in Vojvodina every hour, 24 hours forward. The UVI forecasts have been publicly available at the website of the Faculty of Sciences (PMF), University of Novi Sad. The future efforts will be done to make this empirical model for UVI forecast in the Republic of Serbia. For that, UVA factor will be modified to account the atmospheric extinction from molecular scattering and aerosols at every site. Also, for the non-flat areas in the Republic of Serbia influence of the altitude on UVI should be included $[5,6]$.

Acknowledgements: The paper is a part of the research done within the project "Studying climate change and its influence on the environment: impacts, adaptation and mitigation" (III43007) financed by the Ministry of Education and Science of the Republic of Serbia within the framework of integrated and interdisciplinary research and technological development for the period of 2011-2018 and the research done within the project III 43008 financed by Republic Ministry of Education, Science and Technological Development. 


\section{REFERENCES}

1. F. McKinlay, B. L. Diffey, "A reference action spectrum for ultraviolet induced erythema in human skin, CIE Research note” CIE J., vol. 6, no. 1, pp. 17 - 22, 1987.

2. P. Koepke et al., "Comparison of Models Used for UV Index Calculations," Photochem. Photobiol. vol. 67, no. 6, pp. 657 - 662, Jun. 1998.

DOI: 10.1111/j.1751-1097.1998.tbo9109.x PMid: 9687266

3. M. Allaart et. al., "An empirical model to predict the UV-index based on solar zenith angles and total ozone," Meteorol. Appl. vol. 11, no. 1, pp. 59 - 65, Mar. 2004.

DOI: $10.1017 / \mathrm{S} 1350482703001130$

4. Report of the WMO Meeting of Experts on $U V-B$ Measurements, Data Quality and Standardization of UV Indices, WMO TD No. 625, WMO, Les Diableretes, Switzerland, 1994.
Retrieved from: http://ds.data.jma.go.jp/qasac/report/ gaw095.pdf;

Retrieved on: Aug. 21, 2018

5. N. Chubarova et al., "A new parameterization of the UV irradiance altitude dependence for clear-sky conditions and its application in the on-line UV tool over Northern Eurasia," Atmos. Chem. Phys. vol. 16, no. 18, pp. $11867-11881$, Sep. 2016. DOI: $10.5194 /$ acp-16-11867-2016

6. Y. Sola et al., "Altitude effect in UV radiation during the Evaluation of the Effects of Elevation and Aerosols on the Ultraviolet Radiation 2002 (VELETA-2002) field campaign," J. Geophys. Res-Atmos, vol. 113, no. D23, D23202, Dec. 2008.

DOI: 10.1029/2007JDoo9742 